Article

\title{
The Potential Use of Car Windscreens for Post-Accident Dose Reconstruction in the Periphery of Nuclear Installations
}

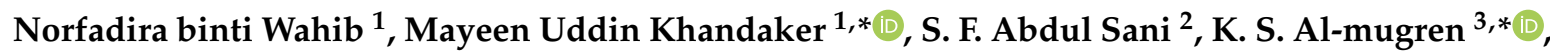 \\ D. A. Bradley ${ }^{1,4}$, A. Sulieman ${ }^{5}\left(\mathbb{D}\right.$, Mohammad Rashed Iqbal Faruque ${ }^{6}(\mathbb{D})$ and M. I. Sayyed ${ }^{7,8}$ \\ 1 Centre for Biomedical Physics, School of Healthcare and Medical Sciences, Sunway University, \\ Bandar Sunway 47500, Selangor, Malaysia; n.wahib@adfa.edu.au (N.b.W.); d.a.bradley@surrey.ac.uk (D.A.B.) \\ 2 \\ 3 Der 4 Der \\ Space Science Centre (ANGKASA), Universiti Kebangsaan Malaysia, UKM, Bangi 43600, Selangor, Malaysia; \\ rashed@ukm.edu.my \\ 7 Department of Physics, Faculty of Science, Isra University, Amman 11622, Jordan; mabualssayed@ut.edu.sa \\ 8 Department of Nuclear Medicine Research, Institute for Research and Medical Consultations, Imam \\ Abdulrahman bin Faisal University, Dammam 31441, Saudi Arabia \\ * Correspondence: mayeenk@sunway.edu.my (M.U.K.); ksalmogren@pnu.edu.sa (K.S.A.-m.)
}

Received: 10 September 2020; Accepted: 9 October 2020; Published: 13 October 2020

check for updates

\begin{abstract}
Cars of a variety of brands are usually parked at a fixed but increasing distance in the periphery of nuclear installations. Herein we focus on the potential use of car windscreens for post-accident dose reconstruction from unplanned nuclear events and natural disasters, also in regard to unexpected events arising during large-scale use of radioactive and nuclear materials. The situation requires identification of analytical techniques that could both readily and reliably be used to assess absorbed dose, sufficient to prompt remedial action where necessary. Samples from three widely used car brands-Honda, Toyota and Proton-are studied in respect of their thermoluminescence (TL) yield. Key TL dosimetric features in the gamma-ray dose range of 1-100 Gy are examined. An ERESCO model 200 MF4-RW X-ray machine has also been used for energy response studies; a Harshaw 3500 TLD reader equipped with WinREMS software was used for the luminescence measurements. All brands exhibit linearity of TL yield versus dose, the samples from Honda showing the greatest response followed by that of the Toyota and Proton brands. The marked energy dependence reflects the effect of the strongly Z-dependent photoelectric effect. Signal fading was investigated over a period of 28 days, the Toyota and Proton brand windshield glass showing a relatively low loss at $52.1 \%$ and $52.6 \%$ respectively compared to a $56.7 \%$ loss for that of the Honda samples. This work forms the first such demonstration of the potential of car windshield glass as a retrospective accident dosimeter.
\end{abstract}

Keywords: widely used car brands; windscreen glass; X-ray and $\gamma$-ray exposure; thermoluminescence technique; retrospective dosimetry

\section{Introduction}

Retrospective dosimetry via simulations and measurements form the basis of dose reconstruction studies that are aimed at assessing the dose received by individuals. Focusing on the need to deal with accidental exposure situations, the lack of formal dosimeters represents a serious challenge 
in obtaining reliable estimates of individual dose. The problems can become that much more difficult when they concern mass exposure events, as in for instance nuclear accidents on the scale of Fukushima and Chernobyl. In terms of numbers alone, concerns naturally turn towards non-monitored individuals (non-radiation workers and members of the public) some of whom may need immediate medical attention, including as radiological casualties. In such situations, well-informed triage is required, including the need for dosimetric information derived from convenient media that are commonly available within the immediate environs of an accident, simple dose readout also being available. The potential materials should have serviceable sensitivity to ionizing radiation, be minimally hygroscopic and have the ability to retain dose-dependent data for a convenient period of time post-exposure.

In responding to such challenges, the thermoluminescence (TL) technique is one of the more commonly cited choices. In particular, it offers a potential for versatile functionality, including energy absorption linked to time-integrated dose stored over a reasonably long period of time, needing to be sufficient to allow for delays in reconstruction of radiation exposure. This passive form of dosimetry offers freedom from a number of complexities, not least being very much less expensive than most if not all active and/or radioluminescence systems. In addition, the TL method requires simple sample preparation and use of well-established measurement protocols that are much less demanding compared to other alternative techniques [1,2]. Note that TL systems can possess superior signal to that of optically stimulated luminescence (OSL) and electron paramagnetic resonance (EPR), with a potential for measuring a broader spectrum of light emission, also suffering much less fading, especially in situations in which the TL analysis concerns elevated temperature glow peaks signals.

In regard to translucent amorphous media, commercially available glass included, TL is interpretable on the basis of elementary energy band theory. In this, charge carriers (electron and holes) are trapped in allowed states within the forbidden gap, directly linked to for instance impurity defects and strain-related network imperfections [3]. Such trapping and luminescence centres are largely responsible for the TL emission phenomenon, heating subsequent to exposure allowing free migration of the electrons and holes in the lattice, sometimes re-trapping but otherwise recombining, the consequence of which is photon emission [4]. In a good thermal conductor luminescence emission intensity can be prompt, temperature-dependence leading to the exhibition of one or more thermoluminescence peaks. Specifically, whenever unoccupied traps continue to exist and atomic displacements are not generated, the emitted light intensity can be expected to be proportional to the radiation flux (absorbed dose) of the material.

Developments towards retrospective TL dosimetric assessment and the availability of convenient materials have attracted the attention of researchers worldwide. Potential media include porcelain $[5,6]$, bricks [7], mobile phone screens [8-10], and various other types of glass [1,11-15], all investigated owing to a number of favorable radiation dosimetry properties. One such desire is for detection of a wide range of doses, from low to high, in this respect glassy materials providing significant interest, also as a result of their widespread use within the built environment as well as fast sample preparation, further offering a manifest barrier to moisture as well as natural transparency at optical wavelengths [1].

In regard to prospects for car windshield glass as a retrospective thermoluminescence dosimeter, evidence of previous such a study has not been found within the literature. Consequently, the present study examines the TL properties of this form of glass, a random choice being made of three locally popular car brands (Proton, Toyota and Honda) to provide a proof of principle. The samples were subjected to X-and $\gamma$-ray irradiation, with doses in the range 1-100 Gy, characterization being made of key dosimetric properties including the TL glow curve, sensitivity to dose, energy response and fading. Material composition and effective atomic number $\left(Z_{\text {eff }}\right)$ were also evaluated, dose evaluation needing to finally correspond with that of soft tissue, pointing to a demand for careful calibration in finally reconstructing the received dose. 


\section{Materials and Methods}

As previously mentioned, study was made herein of windshield glass samples from three popular brands of motor car-Proton, Toyota and Honda (Table 1). All glass samples were obtained from motor mechanic shops/garages/workshops in Kuala Lumpur, subsequently taken to the radiation laboratory at the University of Malaya for preparation and analysis. All of the samples were thoroughly cleaned, crushed into smaller pieces, ground using a pestle and mortar, and collected in the form of a homogenous powder form, sieving through a 180 micrometer mesh filter (Thermo Fisher Scientific, Waltham, MA, USA). All of the samples were weighed using an electronic balance (Mettler Toledo model, Greifensee, Switzerland), TL yield needing to be normalized to unit sample mass, in present work chosen to be some 40 to $50 \mathrm{mg}$ per sample to ensure accommodation in the planchet of the TLD reader. Prior to irradiation, the samples were annealed at a temperature of $400{ }^{\circ} \mathrm{C}$ for $1 \mathrm{~h}$ in order to mitigate any residual stored luminescence, emptying the high temperature traps and interstitials. During the annealing process, the glass samples were placed in a ceramic pot and wrapped using aluminum foil in order to prevent contamination of the samples from residuals in the multi-user furnace. At switch-off the samples were then retained within the furnace (model MB3, CMTS Sdn. Bhd, Selangor, Malaysia) for a period of $24 \mathrm{~h}$, allowing non-forced cooling in order to reduce additional thermal stress to the samples.

The glass samples were irradiated to doses from 1 to $100 \mathrm{~Gy}$ using a ${ }^{60} \mathrm{Co}$ gamma source (gamma dose-rate of $1.43 \mathrm{~Gy} / \mathrm{min}$ at the time of the study), while an ERESCO model 200 MF4-RW X-ray machine was used in carrying out energy dependence analysis, both facilities being located at the Department of Physics, University of Malaya. Pre- and post-irradiation, the samples were kept in light-tight containment in order to reduce any exposure to ambient light levels. The irradiated samples were readout using a Harshaw TLD Model 3500 reader (Waltham, MA, USA) equipped with WinREMS software (version PL-26732.8.0.0.0, Thermo Scientific ${ }^{\mathrm{TM}}$, Oakwood Village, OH, USA). All of the samples were readout under a fixed settings regime, as follows; time-temperature profile (TTP) with a pre-heat temperature of $50{ }^{\circ} \mathrm{C}$, a heating rate of $10^{\circ} \mathrm{C} / \mathrm{s}$, an acquisition time of $45 \mathrm{~s}$ and a maximum temperature of $500{ }^{\circ} \mathrm{C}$. Samples were readout under a slow flow of nitrogen gas, suppressing oxidation of the heating element and glass samples. TL signal intensity was recorded in nano-coulomb $(\mathrm{nC})$, each measurement being made by subtracting the background TL response. Scanning Electron Microscope/Energy Dispersive X-ray spectroscopy (SEM/EDX) was carried out using a series TM4000 Table Top SEM (Hitachi, Tokyo, Japan), thus obtaining elemental the compositional analysis of the glass samples (Table 2). A typical SEM image and EDX spectrum are shown in Figure 1.

Table 1. Details of windshield glass samples used in this study.

\begin{tabular}{ccc}
\hline Brand Name & Country of Origin & Average Mass (g) \\
\hline Proton & Malaysia & $0.050 \pm 0.002$ \\
Toyota & Japan & $0.040 \pm 0.003$ \\
Honda & Japan & $0.040 \pm 0.002$ \\
\hline
\end{tabular}

\section{Results and Discussion}

\subsection{Effective Atomic Number}

Effective atomic number $\left(Z_{\text {eff }}\right)$, the key in seeking accurate estimation of absorbed dose, recognizes that the different photon interaction processes provide different weights to the atomic numbers, different in the different energy regions in which the particular processes dominate. With multi-element materials clearly not being represented by a single atomic number, $Z_{\text {eff }}$ is conventionally considered to be a 
suitable parameter in describing multi-element materials within particular photon energy regions [16]. The well-established Mayneord equation [17] is typically used to calculate $Z_{\text {eff }}$ as follows:

$$
Z_{e f f}=\left(a_{1} Z_{1}^{m}+a_{2} Z_{2}^{m}+\cdots+a_{n} Z_{n}^{m}\right)^{\frac{1}{m}}
$$

with $a_{1}, a_{2}, a_{3} \ldots a_{n}$ the fractional weight contributions of each element in the material, obtained from the ratio of number of electrons per gram of each element to the total number of electrons within the mixture, $a_{i}=\frac{n_{e}}{n_{e t}}$, while $m=2.94$, a value typically adopted for photon practical purposes [18], reflective of the dominance of the photoelectric effect in multiple scattering events, the latter being expected in bulk media, humans included.

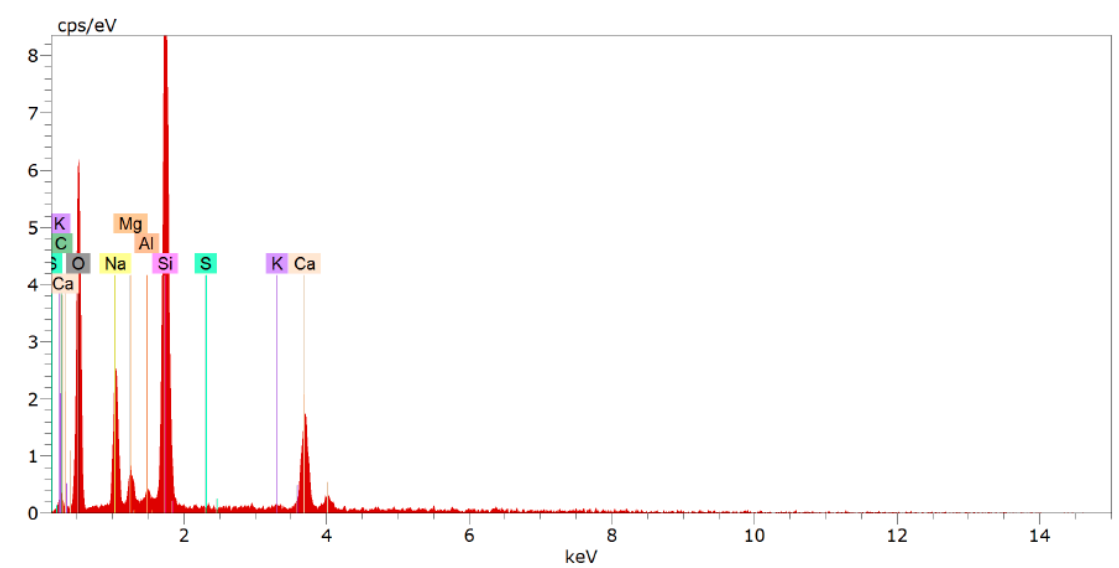

(a)

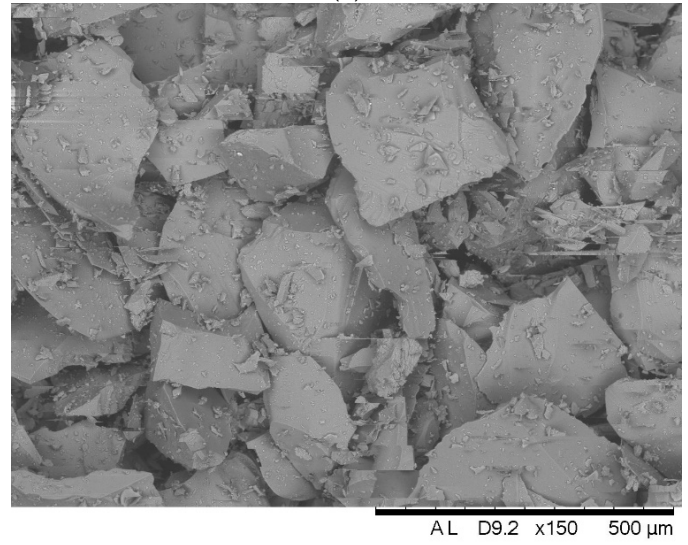

(b)

Figure 1. EDX output from a Honda windshield sample (a) and associated SEM image (b).

Based on the weight fraction values obtained in use of Energy Dispersive X-ray (EDX) spectroscopy and listed in Table 2, the number of electrons per gram of material can be calculated using the following Equation (2) [19];

$$
\mathrm{Ne}=\frac{N_{A} \mathrm{Z}}{A_{W}} \mathrm{~W}_{\mathrm{i}}
$$

with $N_{A}$ the Avogadro number $\left(6.02 \times 10^{23}\right), A_{w}$ atomic weight, $\mathrm{W}_{\mathrm{i}}$ fractional weight and $\mathrm{Z}$ atomic number.

Table 2 shows the greater constituency of the three windshield samples, with as an example oxygen contributing $50.9 \%$ of the mass of Honda windshields (the $Z_{e f f}$ of this medium $=12.2$ ), $50.6 \%$ of the mass of Toyota windshields (the $Z_{\text {eff }}$ of this medium $=12.0$ ) and $50.3 \%$ of the mass of Proton windshields (the $Z_{\text {eff }}$ of this medium $=11.8$ ). 
Table 2. Elemental composition of car windshield glass samples from EDX analysis.

\begin{tabular}{|c|c|c|c|c|c|}
\hline $\begin{array}{l}\text { Windshield Glass } \\
\text { from Car Brand }\end{array}$ & Element, i & $\begin{array}{l}\text { Weight Fraction, } \\
\mathrm{W}_{\mathrm{i}}(\%)\end{array}$ & $\begin{array}{c}\text { No of Electrons per gram of } \\
\text { Each Element, } \\
N_{e}=\left(N_{A} \times Z \times W_{i}\right) / A_{W}\end{array}$ & $\begin{array}{l}\text { Fractional Weight Contributions of } \\
\text { Each Element, } a_{i}\end{array}$ & $\begin{array}{l}\text { Effective Atomic } \\
\text { Number, } Z_{\text {eff }}\end{array}$ \\
\hline \multirow{8}{*}{ Honda } & $\mathrm{Si}$ & 24.8 & $7.43 \times 10^{22}$ & $2.48 \times 10^{-1}$ & \multirow{8}{*}{12.2} \\
\hline & $\mathrm{Na}$ & 8.06 & $2.32 \times 10^{22}$ & $7.75 \times 10^{-2}$ & \\
\hline & $\mathrm{K}$ & 0.05 & $1.46 \times 10^{20}$ & $4.88 \times 10^{-4}$ & \\
\hline & $\mathrm{C}$ & 5.05 & $1.52 \times 10^{22}$ & $5.07 \times 10^{-2}$ & \\
\hline & $\mathrm{O}$ & 50.9 & $1.53 \times 10^{23}$ & $5.11 \times 10^{-1}$ & \\
\hline & $\mathrm{Ca}$ & 8.88 & $2.67 \times 10^{22}$ & $8.91 \times 10^{-2}$ & \\
\hline & $\mathrm{Mg}$ & 1.68 & $4.99 \times 10^{21}$ & $1.67 \times 10^{-2}$ & \\
\hline & $\mathrm{Al}$ & 0.61 & $1.77 \times 10^{21}$ & $5.91 \times 10^{-3}$ & \\
\hline \multirow{8}{*}{ Toyota } & $\mathrm{Si}$ & 24.7 & $7.40 \times 10^{22}$ & $2.47 \times 10^{-1}$ & \multirow{8}{*}{12.0} \\
\hline & $\mathrm{Na}$ & 8.96 & $2.58 \times 10^{22}$ & $8.62 \times 10^{-2}$ & \\
\hline & $\mathrm{K}$ & 0.27 & $7.90 \times 10^{20}$ & $2.64 \times 10^{-3}$ & \\
\hline & $\mathrm{C}$ & 4.8 & $1.44 \times 10^{22}$ & $4.82 \times 10^{-2}$ & \\
\hline & $\mathrm{O}$ & 50.6 & $1.52 \times 10^{23}$ & $5.08 \times 10^{-1}$ & \\
\hline & $\mathrm{Ca}$ & 7.27 & $2.18 \times 10^{22}$ & $7.30 \times 10^{-2}$ & \\
\hline & $\mathrm{Mg}$ & 2.35 & $6.98 \times 10^{21}$ & $2.33 \times 10^{-2}$ & \\
\hline & $\mathrm{Al}$ & 1.14 & $3.31 \times 10^{21}$ & $1.10 \times 10^{-2}$ & \\
\hline \multirow{9}{*}{ Proton } & $\mathrm{Si}$ & 28.8 & $8.64 \times 10^{22}$ & $2.89 \times 10^{-1}$ & \multirow{9}{*}{11.8} \\
\hline & $\mathrm{Na}$ & 9.85 & $2.84 \times 10^{22}$ & $9.48 \times 10^{-2}$ & \\
\hline & K & 0.10 & $2.93 \times 10^{20}$ & $9.78 \times 10^{-4}$ & \\
\hline & $\mathrm{C}$ & 2.12 & $6.38 \times 10^{21}$ & $2.13 \times 10^{-2}$ & \\
\hline & $\mathrm{O}$ & 50.3 & $1.51 \times 10^{23}$ & $5.06 \times 10^{-1}$ & \\
\hline & $\mathrm{Ca}$ & 5.16 & $1.55 \times 10^{22}$ & $5.18 \times 10^{-2}$ & \\
\hline & $\mathrm{Mg}$ & 2.48 & $7.37 \times 10^{21}$ & $2.46 \times 10^{-2}$ & \\
\hline & $\mathrm{Al}$ & 0.96 & $2.78 \times 10^{21}$ & $9.31 \times 10^{-3}$ & \\
\hline & $\mathrm{S}$ & 0.22 & $6.61 \times 10^{20}$ & $2.21 \times 10^{-3}$ & \\
\hline
\end{tabular}


We note that, as the oxide glasses are not conductive, the Au coating was used in the preparation of the SEM analysis, and the carbon tape was utilized as the conductive "bridge" connected from the top surface of the sample to the sample holder. In this matter, the employment of carbon tape may contribute to the low weight fraction percentage of carbon content in the studied samples. The effective atomic number of soft tissues for humans is typically taken to be 7.22, TL results need to be corrected via careful calibration in the final reconstruction of absorbed dose to the human body [20].

\subsection{TL Glow Curve}

The area under the TL glow curve represents luminescence emission over the effective temperature range that elicits dose-dependent trap emptying. Rich in detail, it provides information on TL yield, trap depth and signal fading properties of the materials. Ideally, the TL dosimeter should have glow peak temperatures that are sufficiently great to avoid large-scale fading while at the same time avoiding infrared heating cavity emission issues. In particular, for retrospective dosimetry one is seeking high thermal stability (i.e., deep-seated electron traps) that provide for useful dose storage, even extending over periods from perhaps a number of weeks to some several months or years.

Figure 2 shows typical glow curves obtained from the windshields of the three brands of vehicle, each sample being irradiated to a test dose of $10 \mathrm{~Gy}$. All the samples reveal a broad curve, peaking between $354-389^{\circ} \mathrm{C}$. The behaviour is common to a number of the previously cited amorphous media that have been investigated for TL dosimetry, the distribution of energy showing none of the signs of discreteness seen for instance in ordered media such as TLD-100. Herein, the peaks have been observed to occur at temperatures well above $250{ }^{\circ} \mathrm{C}$, indicative of samples providing high thermal stability, reflective of deep trapping, an essential requirement for dose reconstruction in retrospective dosimetric applications [1]. As seen in Figure 2, the TL glow peak of the Proton sample displays two peaks, a dominant high-intensity peak at $389 \mathrm{~nm}$ and a low-intensity peak at $280 \mathrm{~nm}$ : a peak at $389 \mathrm{~nm}$ displays 17 times larger than the intensity at the peak of $280 \mathrm{~nm}$. Notably, due to its excellent signal stability, the high intensity peak was significant for dosimetry study; hence, this study focuses primarily on the obtained pronounced peaks. At the various doses, the TL glow curves have been shown to be of identical structure in repeat cycles of annealing and irradiation.

The estimation of three fundamental parameters such as the kinetic order, frequency factor (s), and activation energy (E) can be obtained via the analysis of the shape and size of TL glow peaks. In obtaining the order of kinetic, the geometric factor $\left(\mu_{g}\right)$ was first determined using peak shape method developed by Chen [21] as follows:

$$
\mu_{g}=\frac{\delta}{\omega}=\frac{T_{2}-T_{M}}{T_{2}-T_{1}}
$$

where, $T_{M}=$ temperature at which the maximum TL intensity occur, $T_{1}$ and $T_{2}=$ temperatures on either side of $T_{M}$, corresponding to half-intensity, $\delta=T_{2}-T_{M}$, half width at the high temperature side, $\omega=T_{2}-T_{1}$, the full width at half maximum (FWHM).

By substituting the required values in the aforementioned expression, the geometric factor $\left(\mu_{g}\right)$ for all brands windscreens are found to be between 0.48 and 0.51 (see Table 3), indicating that the recombination process for all samples were within the second-order kinetics. The activation energy (E) is further obtained by using the general expressions given by Chen [21], which is valid for any order of kinetics. The activation energy was calculated using the Equation (4):

$$
\mathrm{E}=\mathrm{C}_{\alpha} \frac{k T_{M}^{2}}{\alpha}-\mathrm{b}_{\alpha}\left(2 \mathrm{k} T_{M}\right)
$$

here $\alpha$ can be either $\delta$ or $\omega$. The values of $C_{\alpha}$ and $b_{\alpha}$ are obtained using the following expressions:

$$
\begin{aligned}
C_{\delta} & =0.976+7.3\left(\mu_{g}-0.42\right) ; b_{\delta}=0 \\
C_{\omega} & =2.52+10.2\left(\mu_{g}-0.42\right) ; b_{\omega}=1
\end{aligned}
$$


Upon obtaining the values of the activation energy, the frequency factor (s) for the windshield car brands can be calculated using the formula in Equation (5) [21];

$$
\mathrm{s}=\frac{\beta E}{k T_{M}^{2}} \exp \left(\frac{E}{k T_{M}}\right)
$$

where $\beta$ is the heating rate that employed in this present study $\left(10 \mathrm{~K} \mathrm{~s}^{-1}\right)$ and $\mathrm{k}$ is the Boltzmann constant $\left(8.62 \times 10^{-5}\right) \mathrm{eV} \cdot \mathrm{K}^{-1}$. Table 3 provides detailed values of activation energy $(\mathrm{E})$ and frequency factor (s) for all studied samples following the substitution of values in Equations (3)-(5). The findings in Table 3 reveal that the activation energy for Proton is the highest, while Toyota is the least. It indicates that windscreen glass sample for Proton has created deeper traps than the any other brands.

Table 3. Estimation of the trapping parameters of windshield glass for different car brands subjected to the dose of $10 \mathrm{~Gy}$ with corresponding maximum temperatures calculated from Chen formula.

\begin{tabular}{ccccc}
\hline $\begin{array}{c}\text { Windshield Glass } \\
\text { from Car Brand }\end{array}$ & $\begin{array}{c}\text { TL Peak Position, } \\
\text { TM (K) }\end{array}$ & $\begin{array}{c}\text { Geometric Factor, } \\
\boldsymbol{\mu}_{\mathbf{g}}\end{array}$ & $\begin{array}{c}\text { Activation Energy } \\
\mathbf{( e V )}\end{array}$ & $\begin{array}{c}\text { Frequency Factor } \\
\mathbf{( s}^{\mathbf{- 1}} \mathbf{)}\end{array}$ \\
\hline Honda & 627.15 & 0.51 & 1.18 & $2.97 \times 10^{10}$ \\
Toyota & 646.15 & 0.49 & 0.83 & $1.86 \times 10^{7}$ \\
Proton & 662.15 & 0.48 & 1.29 & $5.93 \times 10^{10}$ \\
\hline
\end{tabular}

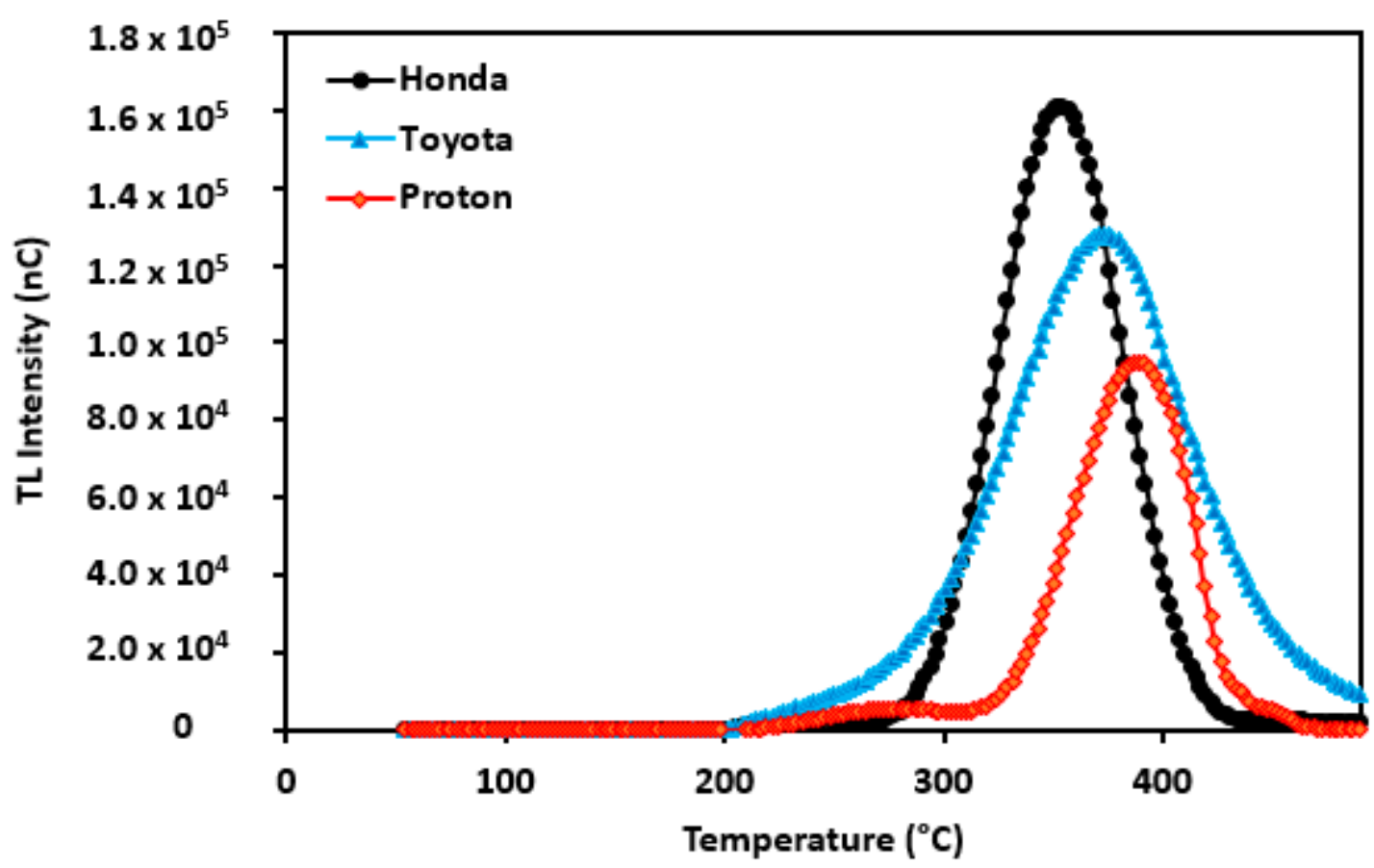

Figure 2. Typical TL glow curve for glass samples from Honda, Toyota and Proton windshields, ${ }^{60} \mathrm{Co}$ irradiated to a fixed dose of $10 \mathrm{~Gy}$.

\subsection{TL Sensitivity}

TL sensitivity is represented as the TL signal per unit dose per unit mass $\left(\mu \mathrm{C} \mathrm{g}{ }^{-1} \mathrm{~Gy}^{-1}\right)$, Figure 3 revealing present results from use of ${ }^{60} \mathrm{Co}$ gamma irradiation. Sample sensitivity with dose is subject to various influencing factors including choice of TLD reader [22] and the means of sample handling. The TL sensitivity graph depicts that all studied samples demonstrate a pronounced low-dose sensitivity relative to high-dose exposure. This is because, as the dose is increased, the concentration of recombination centres may become less than that of the electron traps, thus leads in the reduction of TL sensitivity. Honda windshield glass is observed to produce somewhat better sensitivity throughout the 
studied dose ranges from $0.9 \times$ to $1.3 \times$ of that of the Toyota samples, while the Proton windshield glass is seen to exhibit the least sensitivity. The differences are dominated by relative differences in elemental makeup (Table 2). As instances, the Honda windshield glass shows relatively higher concentrations of fractional $\mathrm{Ca}$, at $8.88 \%$ versus $7.27 \%$ for Toyota and $5.16 \%$ for Proton windshield glass. Variations such as these play significant roles in trap/luminescence centre formation and hence TL sensitivity, in particular the presence of charge states and abundance acting as activators.

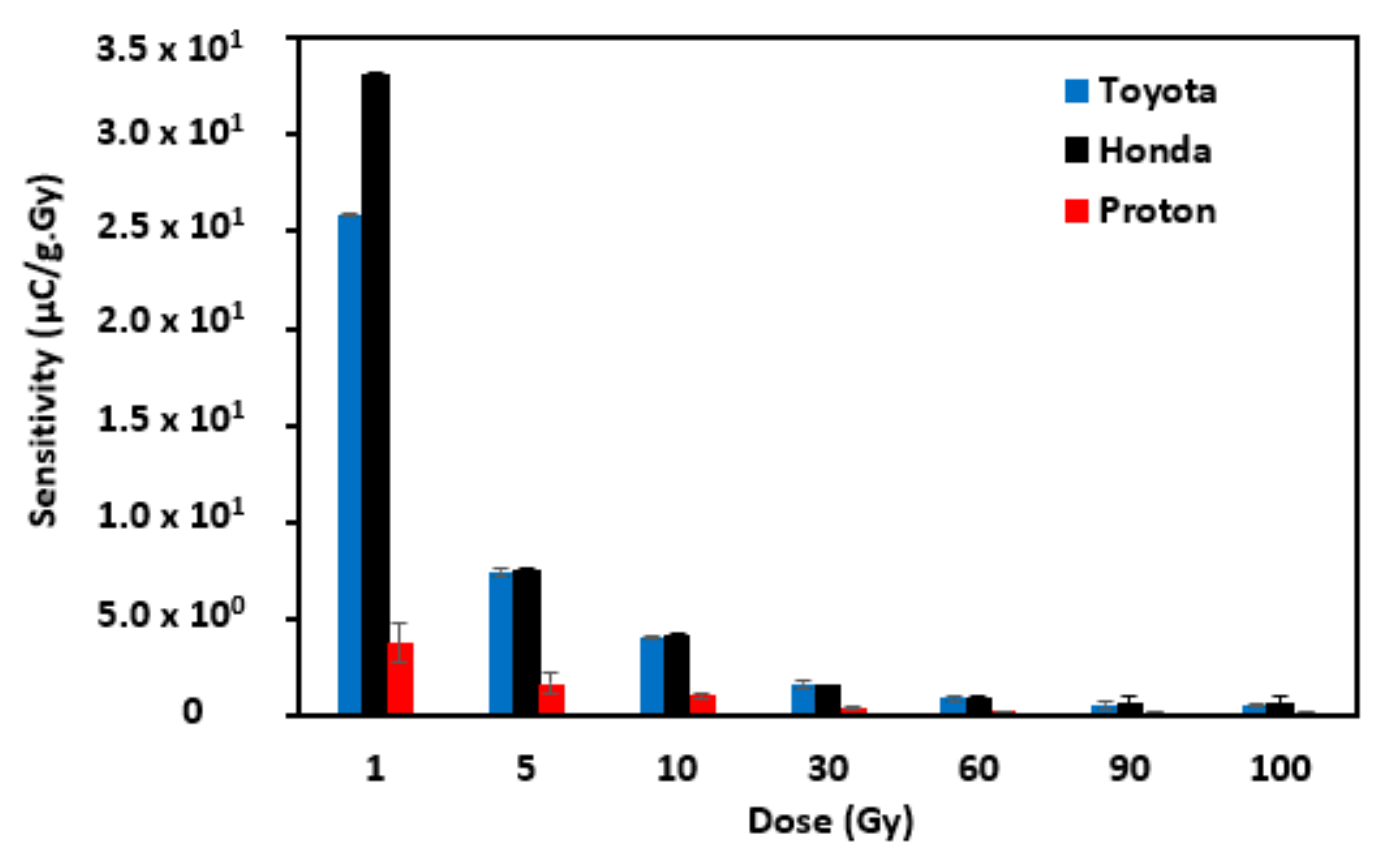

Figure 3. TL sensitivity of glass samples, for doses from 1 to $100 \mathrm{~Gy}$, delivered by ${ }^{60} \mathrm{Co}$.

\subsection{Dose Response}

Figure 4a shows the TL dose response of windshield glass for doses in the range 1 Gy to 10 Gy while Figure $4 \mathrm{~b}$ shows the overall TL response, from $1 \mathrm{~Gy}$ to $100 \mathrm{~Gy}$, inclusive of the lower dose values included in Figure 4a. Highly desirable for a good dosimeter is that it should exhibit excellent linearity of response over a wide range of dose. In Fig. 4 the TL response of each of the glass samples has been normalized to unit mass, each dose point representing the mean of three individual measurements. Good linearity is observed within the two dose regimes, $1 \mathrm{~Gy}$ to $10 \mathrm{~Gy}$ and $10 \mathrm{~Gy}$ to $100 \mathrm{~Gy}$, pointing to the strong potential for use of windshield glass as a retrospective dosimetric base-material. The variations are associated with inhomogeneity in batch samples [23,24]. The Honda windshield provides the greatest response, TL yields being respectively $1.08 \times$ and $1.93 \times$ that of the Toyota and Proton windshields. With a regression coefficient $\left(R^{2}\right)$ of 0.97 , the Honda windshield also offers high dose linearity, the other two vehicle brands showing $R^{2}$ values of greater than 0.76 when taken across the entire dose range, 1 Gy to $100 \mathrm{~Gy}$. Clearly much superior $\mathrm{R}^{2}$ values will be obtained when evaluations are made within the restrictive dose range $10 \mathrm{~Gy}$ to $100 \mathrm{~Gy}$. As seen from Figure 4a,b, the TL intensity for Honda and Toyota car brand samples displayed a significant difference at $1 \mathrm{~Gy}$ and started to diminish further increasing the doses, indicating the possibility of these samples to yield pronounced TL difference in much lower doses. Hence, there is a need for further study on this matter. In more limited study of the TL response of car window glass rather than windshield glass, [25] gave beta doses of 1-10 Gy, showing similarly well-behaved dependency with dose, although in the absence of sampling procedure, brand of car, etc. 
(a)

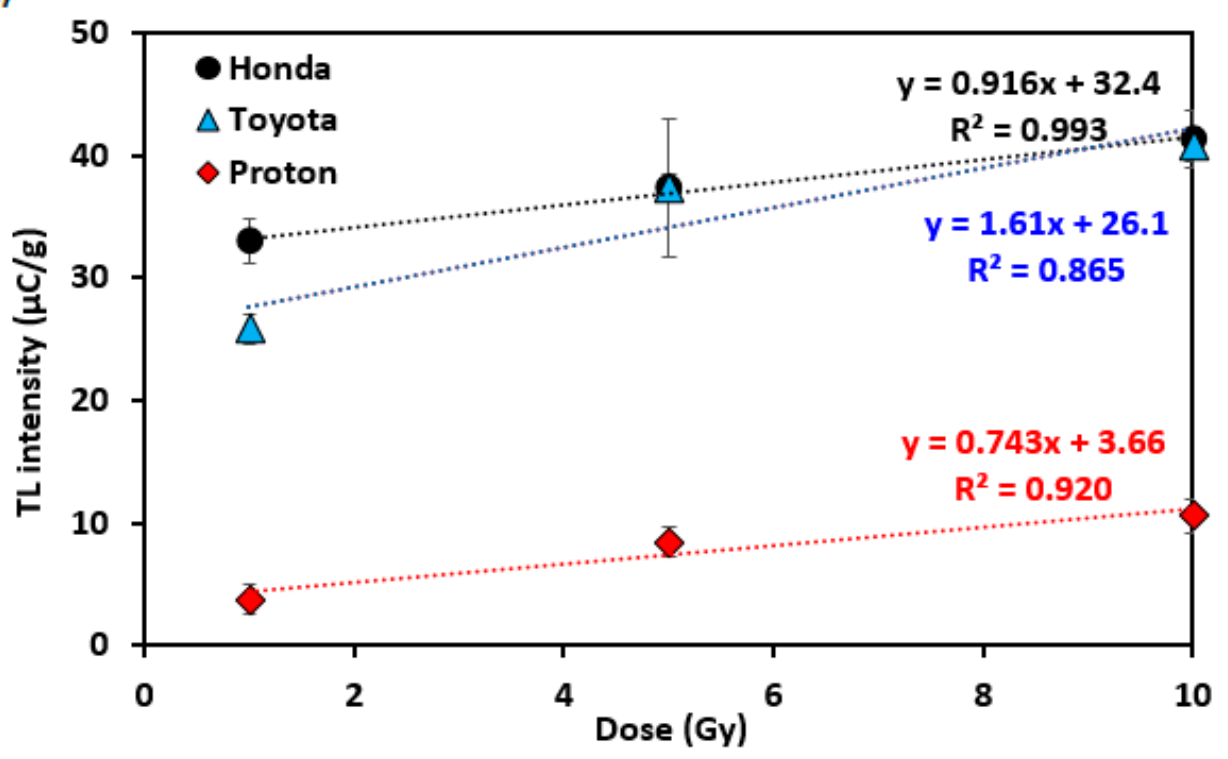

(b)

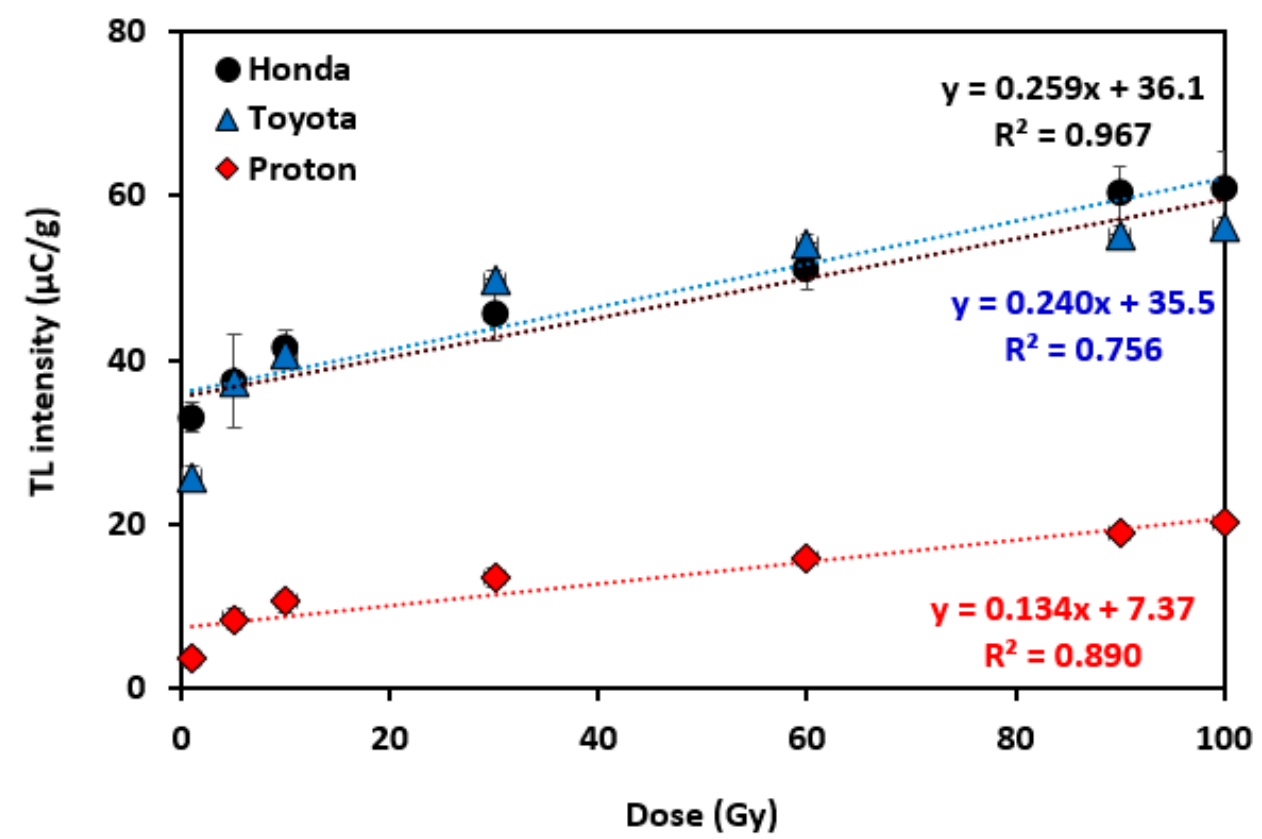

Figure 4. Dose response for ${ }^{60}$ Co exposures: (a) 1-10 Gy; (b) 1-100 Gy. The error bars are standard error of the mean, with in some cases the error bars smaller than the size of the data points. In (b) the linear fittings are biased towards the more elevated doses, (a) better showing the situation at doses up to $10 \mathrm{~Gy}$.

\subsection{Linearity Index, $f(D)$}

Figure 5 illustrates the linearity index, $f(D)$ of the windshield glass samples from the three brands of motor vehicle, $f(D)$ being a measure of deviation from linearity, given by Equation (6):

$$
f(D)=\frac{(M(D) / D)}{\left(M\left(D^{\circ}\right) / D^{\circ}\right)}
$$

with $M(D)$ the TL response at dose $D$ while $M\left(D^{\circ}\right)$ is the TL response at the lowest detected dose, $D^{\circ}$. Linearity is achieved for $f(D)=1$, supra-linearity occuring when $f(D)>1$. The value of 
$f(D)<1$ signifies a saturated or sublinear region as observed when traps trend towards becoming completely filled.

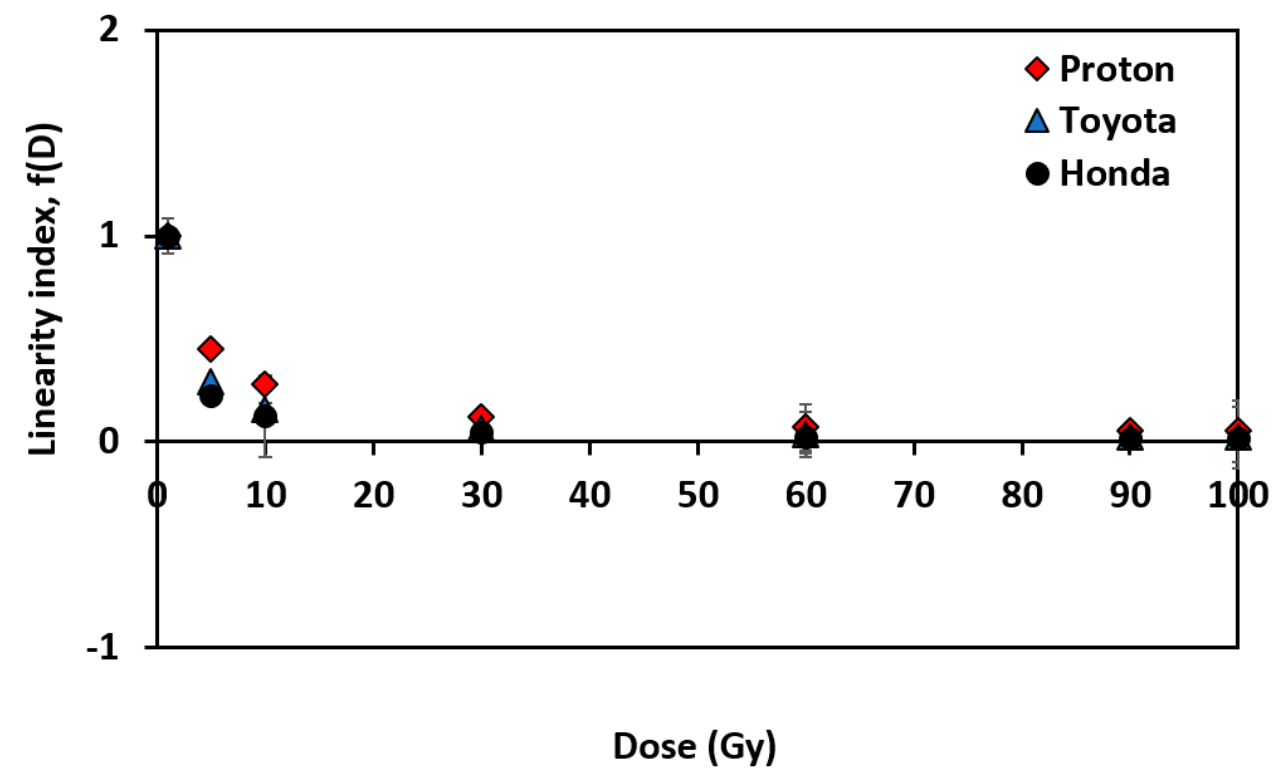

Figure 5. Linearity Index of the glass samples subject to ${ }^{60} \mathrm{Co}$ gamma-irradiation, for doses ranging between 1 Gy to 100 Gy.

From Figure 5, the linearity index for Honda and Toyota samples are mainly overlapped at high doses (60 Gy, 90 Gy and $100 \mathrm{~Gy}$ ) due to the similarity of dose-response behavior; which indicates that the saturation of the signal is likely to be occurred. All of the samples tend towards identical behavior at a practical level, $f(D)$ manifestly decreasing in approaching saturation, recombination and/or radiation damage effects included [26]. Figure 5 also shows the more linear response at lower doses, trending towards sublinearity with increasing dose.

\subsection{Energy Response}

In any photon irradiation dosimetric application, a key characteristic is energy dependence, with present purposes in mind defined as the variation in TL yield at fixed dose versus absorbed energy [27]. The photon-energy dependence was evaluated by exposing the samples to an identical test dose of 1 Gy using an ERESCO 200 MF4-RW X-ray source operated in the range of accelerating potentials of 40 to $120 \mathrm{kVp}$. It is typical in such cases that the energized X-ray tube beams are estimated to have an effective energy of the order of one-third to one-half of the peak $\mathrm{kV}$ values [28]. Hence taking the one-half option, present use of 40,60,80, 100 and $120 \mathrm{kVp}$, translates to effective energies of 20,30, 40, 50 and $60 \mathrm{keV}$. Figure 6 shows the TL response of the samples, the pattern directly linking with the $Z_{\text {eff }}$ values previously obtained and the enhanced response to be expected in this photon energy region in which interactions are dominated by the photoelectric effect [29]. In Figure 6, the observed reduction of TL intensity with energy is a direct reflection of photoelectric dependence, varying inversely with energy modified by attenuation. As such, analytic dependence cannot reasonably be extracted from the quasi power-law fitting. In particular, due to the non-soft tissue equivalence of the glass, suitable calibration would be required to correct for the effect in obtaining the estimated dose to an individual. 


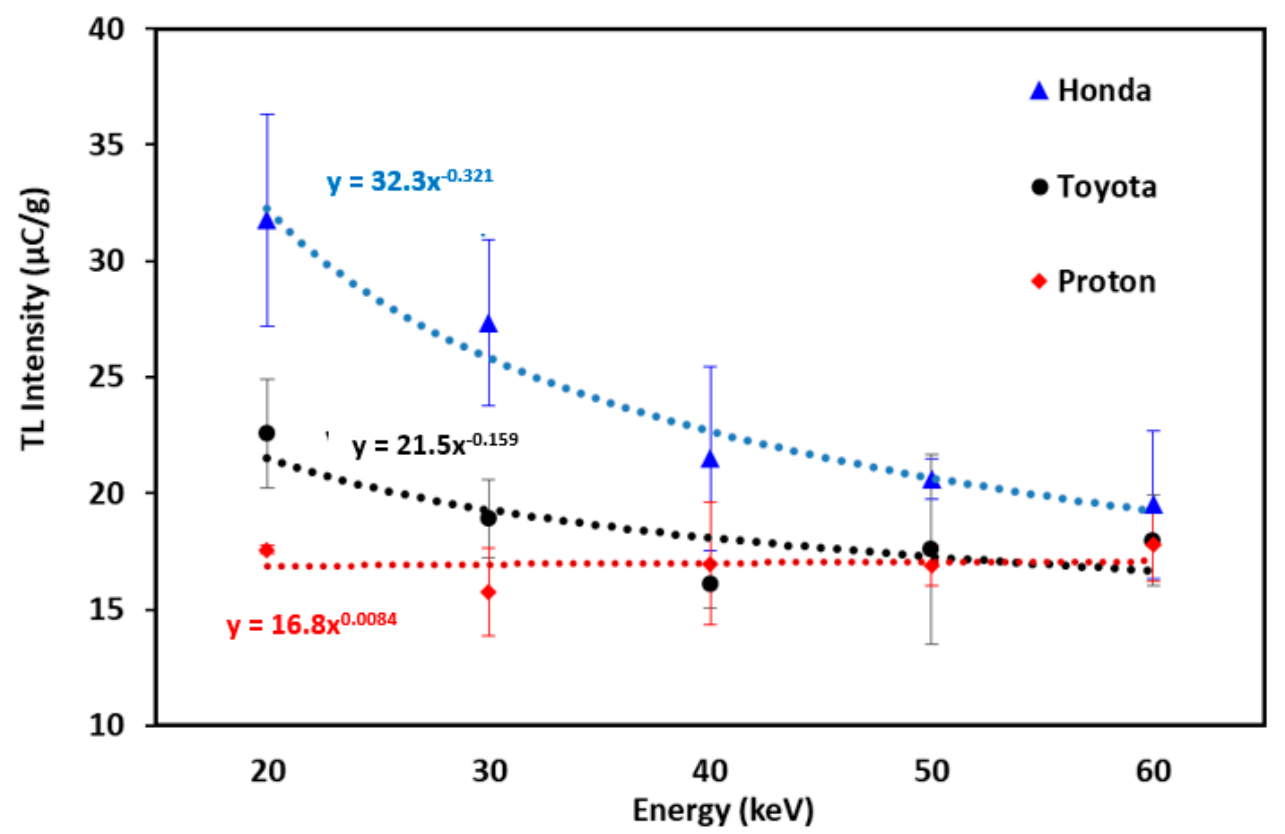

Figure 6. TL response as a function of effective energy $(20-60 \mathrm{keV})$, the samples being subjected to X-ray irradiation.

\subsection{Fading}

The post-irradiation stability of TL signal against time is demonstrated through fading studies [30], as shown herein in Figure 7. The loss of stored signal against time is a thermal relaxation phenomenon, transitions occurring more preferentially from the less stable traps at lower depths. Present study has examined the TL fading over a period of 28 days in seven-day post-irradiation increments. In total, 15 samples were prepared, each irradiated to a fixed dose of $10 \mathrm{~Gy}$ from the ${ }^{60} \mathrm{Co}$ gamma-ray source. Each measurement point is the mean of three repeat readings. TL signal fading is most marked over the first seven days post-irradiation, an unsurprising fact given the greater initial TL signal magnitude, led by the Honda brand motor vehicle windshield glass, then Toyota and Proton, with values of $56.7 \%$, $52.6 \%$ and $52.1 \%$, respectively. In this matter, the windshield for Proton manifests the most stable signal due to the greatest activation energy relative to other car brands. It is apparent that there is good potential for dose reconstruction over a prevailing period of several weeks, corrections needing to be made for the fading, typically using fitting equations as indicated in Figure 7 for the Honda and Proton windshields. The Toyota data shows more complex behavior beyond the initial two weeks post-irradiation, albeit with apparent greater stability within this period. In fact, the fading loss shows proportional to the stored signal (in other words the number of filled defects), such that one might expect a quasi-exponential decrease. It is thus unsurprising that one sees a good fit to the first few terms of an exponential expansion.

Although some progress has been made, further research is required to investigate the fading characteristics at different storage temperatures. This study has found limited efforts in the literature, especially the investigation within the windshield glass. Based on the finding reported by [31], no significant variation was observed on the optical absorbance of commercial window glass at a low storage temperature of $-5{ }^{\circ} \mathrm{C}$ and $-20{ }^{\circ} \mathrm{C}$ that kept for 70 days post-irradiation. In this regard, for the first $24 \mathrm{~h}$, these two sets of samples displayed an approximate reduction of about 5 percent of the optical absorption response. In comparison, low storage temperatures indicate a greater response relative to ambient temperature. In addition, the research to date [32] has published a numerical method in predicting the fading of the TL signal as a function of the trapping parameters for the first, second and general order kinetics. As the values of the order of kinetics increases under the identical 
values of activation energy $\mathrm{E}(\mathrm{eV})$ and pre-exponential factor $\mathrm{S}^{\prime \prime}\left(\mathrm{s}^{-1}\right)$, the fading is predicted to delay due to a high possibility of the electrons re-trapping phenomenon.

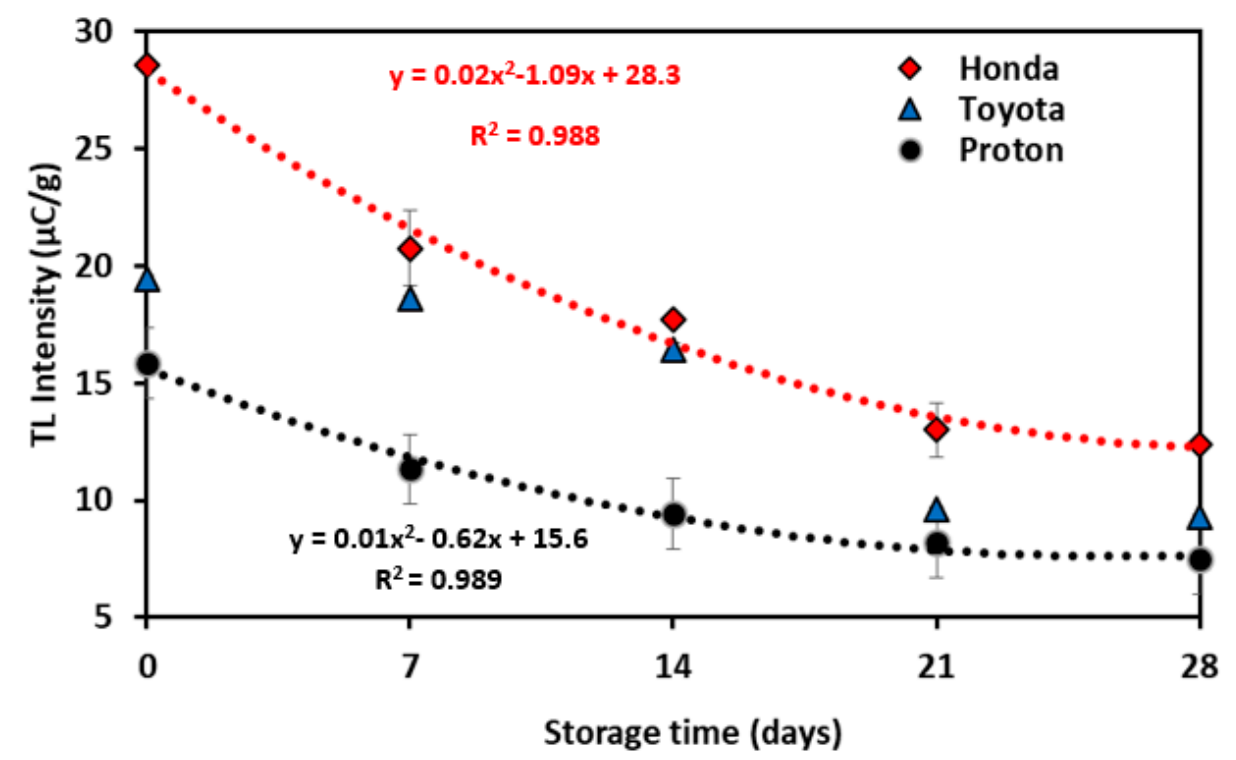

Figure 7. Long-term fading of the TL signal, noting that during periods other than readout the samples are stored in the dark at ambient temperature $\left(27^{\circ} \mathrm{C}\right)$.

\section{Conclusions}

This investigation has evaluated several key TL parameters for windshield glass samples from Honda, Toyota and Proton motor vehicles, including tissue equivalence, TL glow curve, TL sensitivity, dose response, energy response and fading. Over the investigated gamma dose range of 1-100 Gy, the Honda windshield samples are seen to offer the greatest promise, with the greatest TL response and TL sensitivity. With $\mathrm{SiO}_{2}$ the mainstay of glass, Energy Dispersive X-ray Spectroscopy confirms the unsurprising greater presence of both elements, the other various elements being additives that define the various performance properties that are of importance in providing for the needs of high-technology windshields. These same additives undoubtedly give rise to a good deal of the luminescence signal, although the role of the strain-related defects of curved windshields are also to be acknowledged; the effective atomic numbers $\left(Z_{e f f}\right)$ are found to be within the range 11.8-12.2, compared against the $Z_{e f f}$ of TLD-200 (16.3), the latter enjoying popular use in sensitive measurement of low-level environmental radiation. The presence of the other elements, including sodium, potassium, carbon, calcium, magnesium and aluminum, act as impurities which give rise to localized energy levels within the forbidden bandgap, underpinning the occurrence of an appreciable TL yield. Notably, the variation in Ca concentration between the studied windshield glass media is reflected in the TL sensitivity. The glow peaks for all glass samples show a maximum in TL yield for temperatures between $354-389^{\circ} \mathrm{C}$, supportive of the deep trapping (the activation energies are between 0.83 to $1.29 \mathrm{eV}$ ) that is needed for TL media that offer potential for use in retrospective dosimetry. All samples show energy dependency, a matter that needs to be accounted for in obtaining reliable estimates of dose. TL signal storage capability of the three media was investigated for a period of 28 days post-irradiation, demonstrating an ability to retain an appreciable signal for some tens of days post-irradiation. Windshield glass from Honda has been shown to possess the more favourable TL characteristic, a matter needing to be affirmed in more detailed investigations involving greater numbers of samples.

Author Contributions: Conceptualization, M.U.K.; methodology, D.A.B.; software, K.S.A.-m.; validation, S.F.A.S., A.S. and M.I.S.; formal analysis, N.b.W.; investigation, N.b.W.; resources, S.F.A.S.; data curation, N.b.W.; writing-original draft preparation, N.b.W.; writing—review and editing, M.U.K. and D.A.B.; visualization, S.F.A.S., A.S. and M.R.I.F.; supervision, M.U.K.; project administration, M.R.I.F.; funding acquisition, K.S.A.-m. All authors have read and agreed to the published version of the manuscript. 
Funding: This work was funded by Deanship of Scientific Research at Princess Nourah bint Abdulrahman University, through the Fast-track Research Funding (FRF) Program (grant no. 1000-ftfp-20).

Conflicts of Interest: The authors declare no conflict of interest.

\section{References}

1. Yasmin, S.; Khandaker, M.U.; Rozaila, Z.S.; Rashid, M.A.; Bradley, D.A.; Sani, S.F.A. Thermoluminescence features of commercial glass and retrospective accident dosimetry. Radiat. Phys. Chem. 2020, 168, 108528. [CrossRef]

2. Bradley, D.A.; Nawi, S.N.M.; Khandaker, M.U.; Almugren, K.S.; Sani, S.F. Sub kGy photon irradiation alterations in graphite. Appl. Radiat. Isot. 2020. [CrossRef] [PubMed]

3. Horowitz, Y.S.; Chen, R.; Oster, L.; Eliyahu, I. Thermoluminescence theory and analysis: Advances and impact on applications. In Encyclopedia of Spectroscopy and Spectrometry; Elsevier: San Diego, CA, USA, 2016; ISBN 9780128032244.

4. Capelletti, R. Luminescence. In Encyclopedia of Condensed Matter Physics; Elsevier: Amsterdam, The Netherlands, 2005; ISBN 978-0-12-369401-0.

5. Bailiff, I.K. Retrospective dosimetry with ceramics. Radiat. Meas. 1997, 27, 923-941. [CrossRef]

6. Göksu, H.Y.; Stoneham, D.; Bailiff, I.K.; Adamiec, G. A new technique in retrospective TL dosimetry: Pre-dose effect in the $230^{\circ} \mathrm{C}$ TL glow peak of porcelain. Appl. Radiat. Isot. 1998, 49, 99-104. [CrossRef]

7. Singh, A.K.; Menon, S.N.; Kadam, S.Y.; Koul, D.K.; Datta, D. OSL studies of local bricks for retrospective dosimetric application. Nucl. Instrum. Methods Phys. Res. Sect. B Beam Interact. Mater. Atoms 2016, 383, 14-20. [CrossRef]

8. Trompier, F.; Della Monaca, S.; Fattibene, P.; Clairand, I. EPR dosimetry of glass substrate of mobile phone LCDs. Radiat. Meas. 2011, 46, 827-831. [CrossRef]

9. Discher, M.; Woda, C.; Fiedler, I. Improvement of dose determination using glass display of mobile phones for accident dosimetry. Radiat. Meas. 2013, 56, 240-243. [CrossRef]

10. Siti Rozaila, Z.; Khandaker, M.U.; Wahib, N.b.; Hanif bin Abdul Jilani, M.K.; Abdul Sani, S.F.; Bradley, D.A. Thermoluminescence characterization of smartphone screen for retrospective accident dosimetry. Radiat. Phys. Chem. 2020, 167, 108297. [CrossRef]

11. Hashimoto, T.; Takano, M.; Yanagawa, Y.; Tsuboi, T. Radiation dosimetry using thermoluminescence from ceramic and glass samples at the JCO critical accident site. J. Environ. Radioact. 2000, 50, 97-105. [CrossRef]

12. Mizuno, H.; Kanai, T.; Kusano, Y.; Ko, S.; Ono, M.; Fukumura, A.; Abe, K.; Nishizawa, K.; Shimbo, M.; Sakata, S.; et al. Feasibility study of glass dosimeter postal dosimetry audit of high-energy radiotherapy photon beams. Radiother. Oncol. 2008, 86, 258-263. [CrossRef]

13. Jafari, S.M.; Bradley, D.A.; Gouldstone, C.A.; Sharpe, P.H.G.; Alalawi, A.; Jordan, T.J.; Clark, C.H.; Nisbet, A.; Spyrou, N.M. Low-cost commercial glass beads as dosimeters in radiotherapy. Radiat. Phys. Chem. 2014, 97, 95-101. [CrossRef]

14. Bradley, D.A.; Siti Shafiqah, A.S.; Siti Rozaila, Z.; Sabtu, S.N.; Abdul Sani, S.F.; Alanazi, A.H.; Jafari, S.M.; Amouzad Mahdiraji, G.; Mahamd Adikan, F.R.; Maah, M.J.; et al. Developments in production of silica-based thermoluminescence dosimeters. Radiat. Phys. Chem. 2017, 137, 37-44. [CrossRef]

15. Wahib, N.b.; Khandaker, M.U.; Aqilah binti Mohamad Ramli, N.; Sani, S.F.A.; Bradley, D.A. Commercial kitchenware glass as a potential thermoluminescent media for retrospective dosimetry. Appl. Radiat. Isot. 2019, 148, 218-224. [CrossRef] [PubMed]

16. Kurudirek, M. Effective atomic numbers and electron densities of some human tissues and dosimetric materials for mean energies of various radiation sources relevant to radiotherapy and medical applications. Radiat. Phys. Chem. 2014, 102, 139-146. [CrossRef]

17. Mayneord, W. The Significance of the Röntgen. In Unio Internationalis Contra Cancrum; Springer: Berlin, Germany, 1937.

18. Khan, F.M. The Physics of Radiation Therapy, 4th ed.; Lippincott Williams \& Wilkins: Philadelphia, PA, USA, 2009.

19. Al-Sawaf, H.A.; Jassi, K.A.; Sleeman, S.Y. The Effective Atomic Number of Tissue Equivalent Materials. Raf. J. Sci. 2005, 16, 22-27. 
20. Hashim, S.; Saripan, M.I.; Rahman, A.T.A.; Yaakob, N.H.; Bradley, D.A.; Alzimami, K. Effective atomic number of Ge-doped and Al-doped optical fibers for radiation dosimetry purposes. IEEE Trans. Nucl. Sci. 2013. [CrossRef]

21. Chen, R. On the calculation of activation energies and frequency factors from glow curves. J. Appl. Phys. 1969, 40, 570. [CrossRef]

22. Aboud, H.; Saber, S.; Wagiran, H.; Hussin, R. Energy response and thermoluminescence properties of lithium potassium borate Glass co-doped with $\mathrm{Cu}$ and $\mathrm{SnO}_{2}$ nanoparticles. J. Radiat. Res. Appl. Sci. 2017. [CrossRef]

23. Tamrakar, R.K.; Bisen, D.P.; Sahu, I.P.; Brahme, N. UV and gamma ray induced thermoluminescence properties of cubic $\mathrm{Gd}_{2} \mathrm{O}_{3}: \mathrm{Er}^{+}$phosphor. J. Radiat. Res. Appl. Sci. 2014. [CrossRef]

24. Elashmawy, M. Study of constraints in using household $\mathrm{NaCl}$ salt for retrospective dosimetry. Nucl. Instrum. Methods Phys. Res. Sect. B Beam Interact. Mater. Atoms 2018. [CrossRef]

25. Moffatt, J.E.; Spooner, N.A.; Creighton, D.F.; Smith, B.W. Luminescence properties of common glasses for application to retrospective dosimetry. Radiat. Meas. 2012, 47, 851-856. [CrossRef]

26. Horowitz, Y.S. The theoretical and microdosimetric basis of thermoluminescence and applications to dosimetry. Phys. Med. Biol. 1981, 26, 765. [CrossRef] [PubMed]

27. Furetta, C. Handbook of Thermoluminescence; World Scientific Publishing: Singapore, 2003.

28. Bushberg, J.T.; Seibert, J.A.; Leidholdt, E.M.; Boone, J.M. The Essential Physics of Medical Imaging; Lippincott Williams and Wilkins: Philadelphia, PA, USA, 2011.

29. Knoll, G.F. Radiation Detection and Measurement; John Wiley and Sons: New York, NY, USA, 2010; ISBN 9780470131480.

30. McKeever, S.W.S.; Moscovitch, M.; Townsend, P.D. Thermoluminescence Dosimetry Materials: Properties and Uses; Nuclear Technology Publishers: Ashford, Kent, UK, 1995.

31. Fadel, M.A. New approaches in glass dosimetry. Radiat. Eff. 1976. [CrossRef]

32. Bakr, M.; Omer, M. Determination of Thermoluminescence Kinetic Parameters of $\mathrm{La}_{2} \mathrm{O}_{3}$ Doped with Dy ${ }^{3+}$ and $\mathrm{Eu}^{3+}$. Materials 2020, 13, 1047. [CrossRef] 